أمل حسين حجاب

\title{
كتب الكبار
}

$$
\text { راندا عبدالعليم المنير. }
$$

ثقافة الطفل فى ضو ء الاتجاهات المعاصرة /

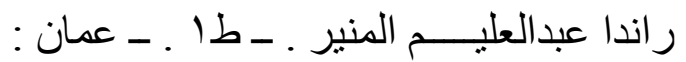

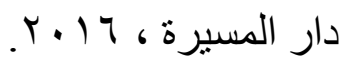

.

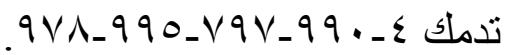

الأطةال - عام نقس

نائلة حسن فائق.

الصحة النفسية فى مرحلة الطفولة المبكرة / لـانئ

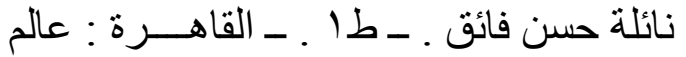

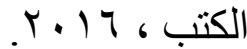

(5

تدمك

\section{الأطفال المعوقون}

إبر اهيم عبداله الزريقات.

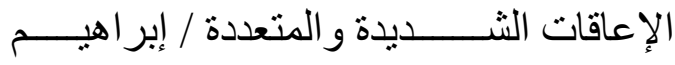

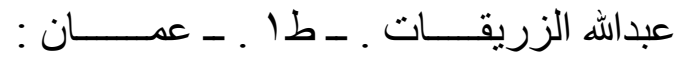

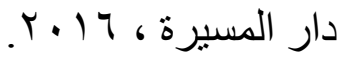

.

تدمك 9 - 1 .

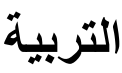

أحمد مصطفى شلبى.

مســــــوليات المعلمين و الآبـــاء نحو التربية

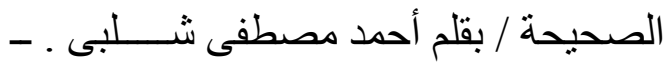

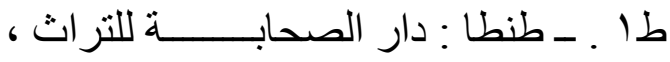

r.17
الأباء والأبناء

أسماء عبد الحسين النجار.

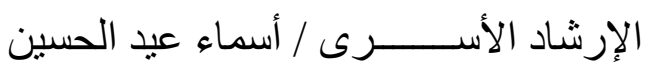

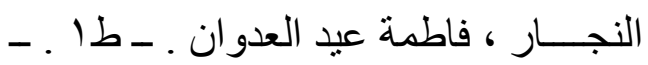

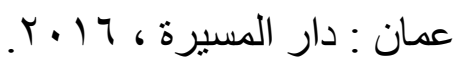

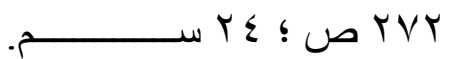

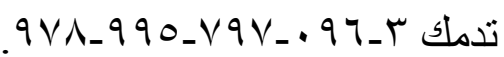

الإثر اف التربوى

أحمد عبداللطيف أبو أسعد.

الإرشــــــاد المدرسـى / أحمد عبداللطيف الطيف

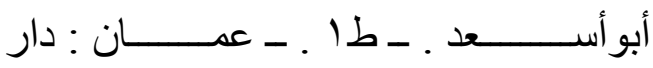

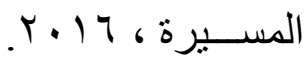

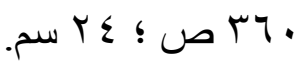

$9 \vee \Lambda_{-} 990 \_\Lambda \cdot 7_{-} 0 \leqslant \vee-\Lambda$ تدمل

صالح أحمد الخطيب.

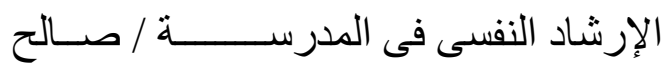

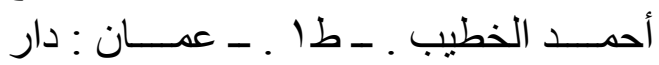

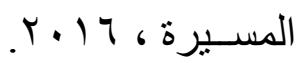

. $r \leqslant \leq \vee \wedge$

تدمك r-1 1. 999 .

الأطفال بطيئو التمليم

عادل محمد العدل.

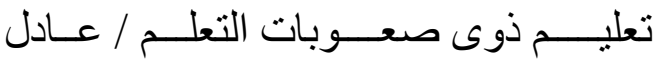

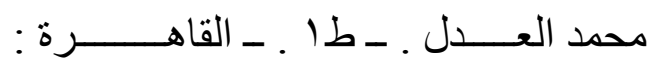

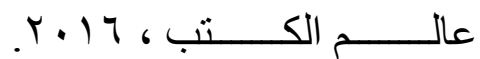
س

تدمك 


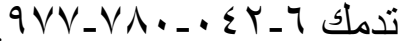

$$
\text { علاء أيوب. }
$$

نظرية الذكاء الناجح : التو افق بين التدريس

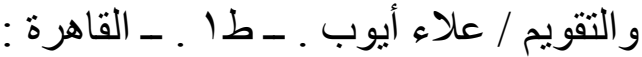

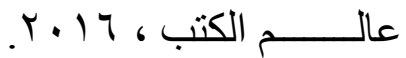

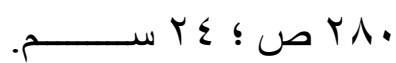

تدمك سك

\section{السينما والأطةال}

أمل إسماعيل عبد الرازق.

الأطفـال وسينما الر عب : در اســة تطبيقية

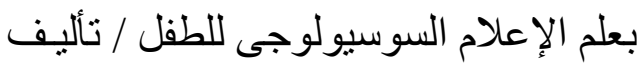

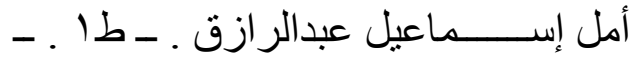

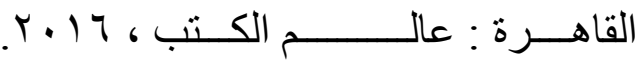
. سـ

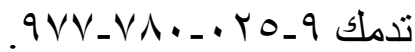

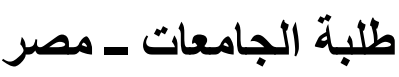
ياسر عبدالكريم بكار. دليل علمى للطــــــاب و والطالبات من أجل

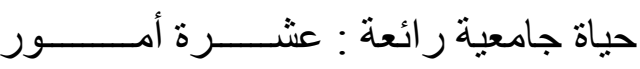

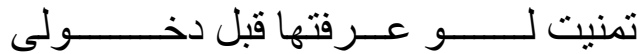

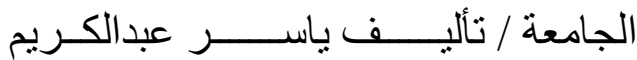

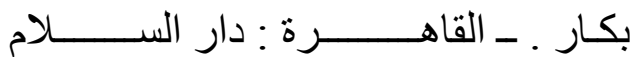

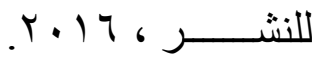
ت 17. . $9 \vee \Lambda_{-} 9 \vee V-V \mid V \_r \wedge \tau_{-} \wedge$ تدمك

عام الiقس محمد السعيد أبو حلاوة.

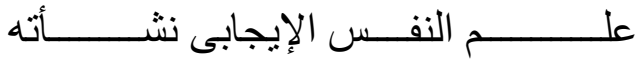

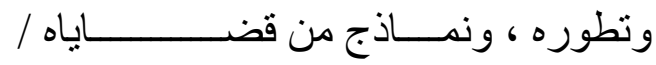

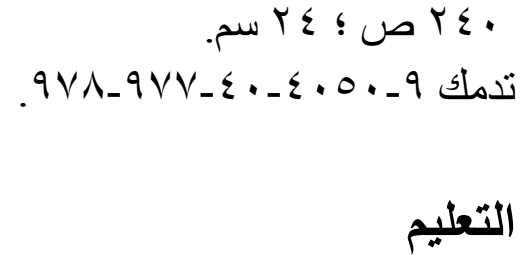

برنامج لتنمية مهار ات التو اصل الثــــفوى

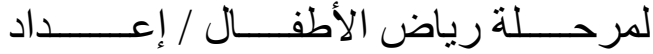

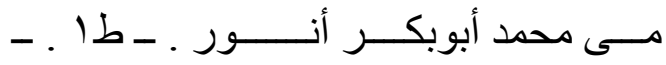

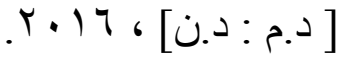

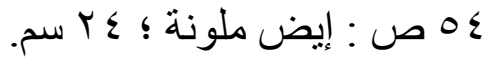

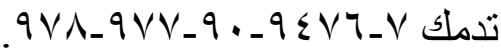

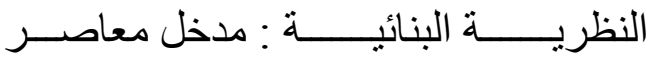

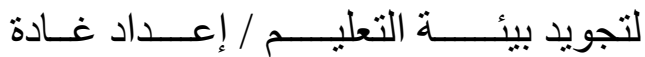

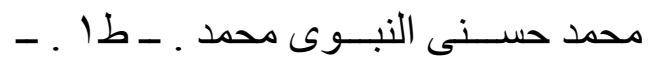

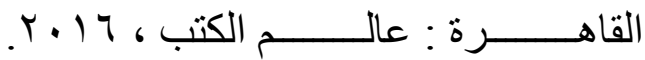
. تدمك

\section{التعليم الثانوى - مصر}

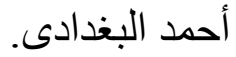

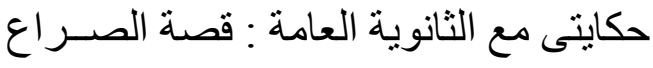

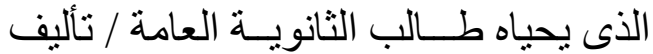

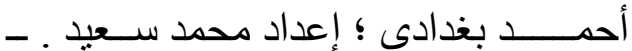

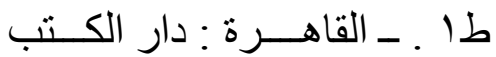

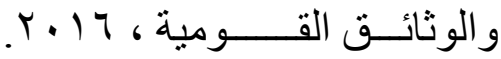

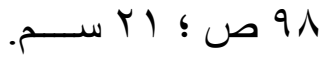

\section{الأكاء}

رشاد على عبد العزيز موسى.

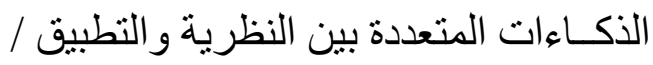
رشاد على عبدالعزيز موسى ـ ـ القاهـرة :

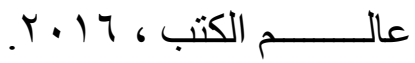
IVT 


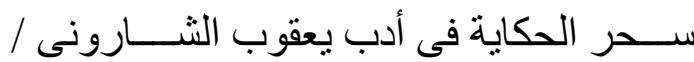

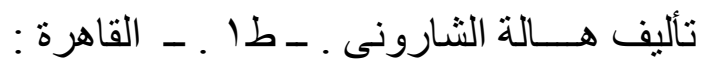

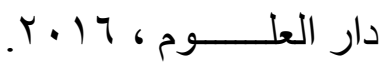
ت

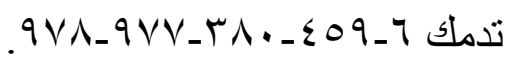

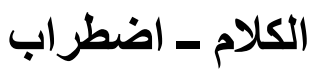

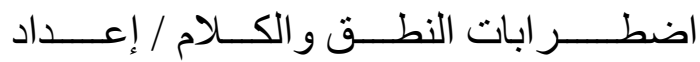

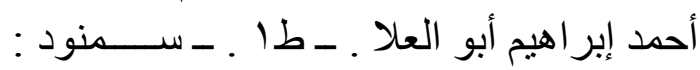

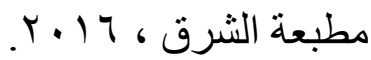
.

\section{المسرح - نقاد} نهاد إبر اهــــــيم.

قر اءات نقدية فى العروض المسرحية (تشكل

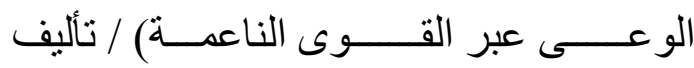

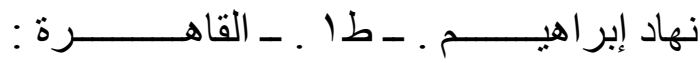

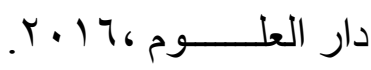
ت تدمك مصر ـ التنمية الاجتماعية

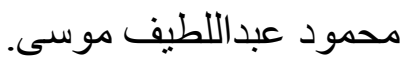

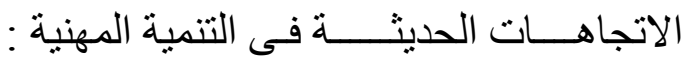

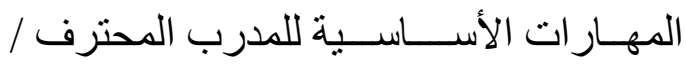

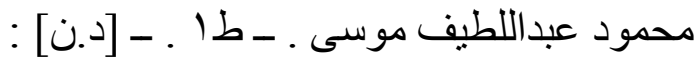

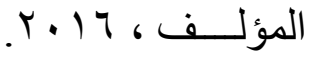
ال

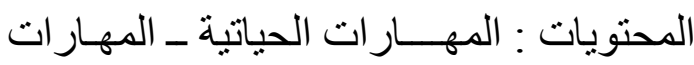
الإداريــــــة ـ المهار ات الفنية.
تأليف محمد الســـــــيد أبو حلاوة ، عاطف

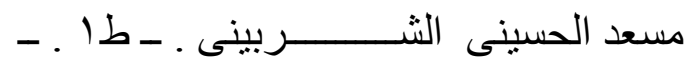

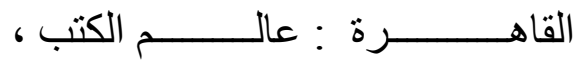
$r+17$ ت. تدمك )

\section{علم النفس التربوى} حسام محمد عز الدين.

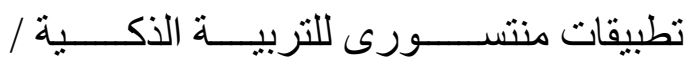

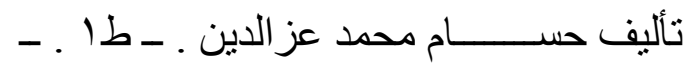

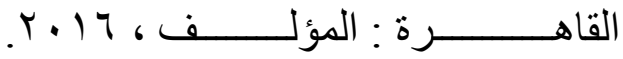

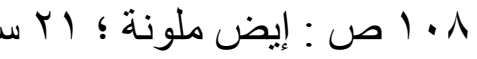

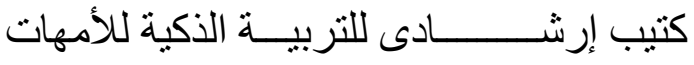
و المدرسات ومديرى رياض الأطفال لأطفـال التال

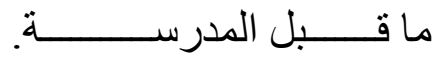
تدمك هل $9 \vee \Lambda_{-}$

عادل صلاح غنايم.

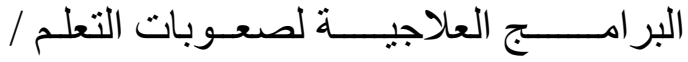

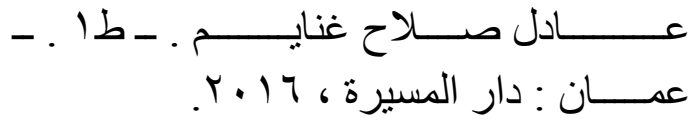
.

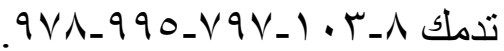

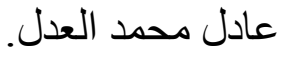

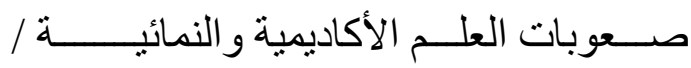

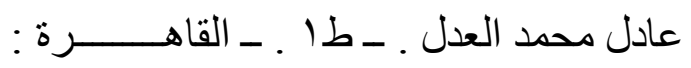

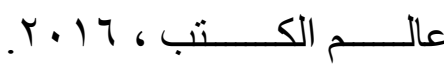
. تدمك ... IT 


\section{المؤسسات الخيرية}

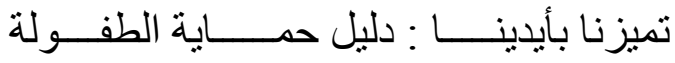

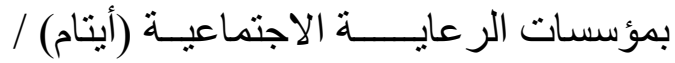

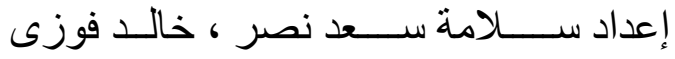

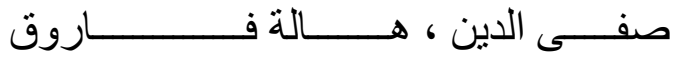

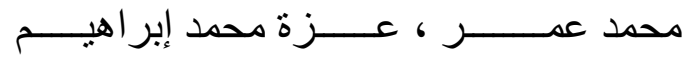

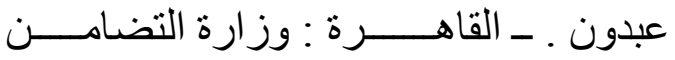

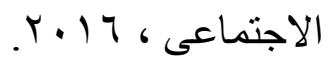
.

\section{وسائل الإعلام}

سماح عبدالرازق الثهاوى.

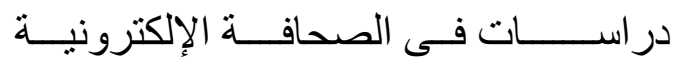

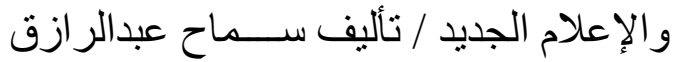

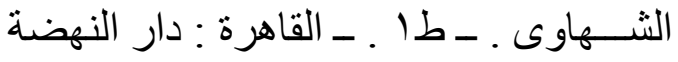

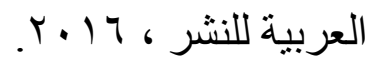
تُ تدمك 


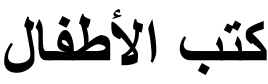

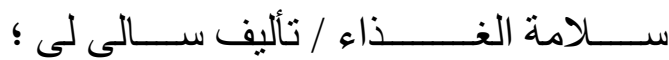

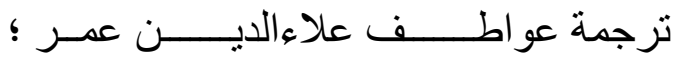

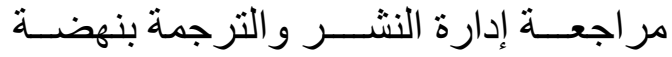

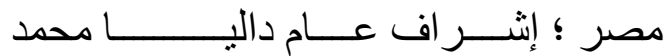

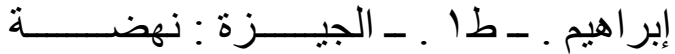

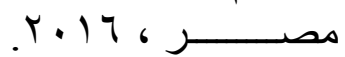

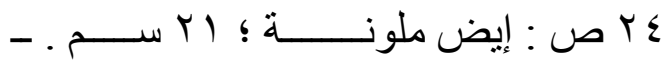
(5) إمن

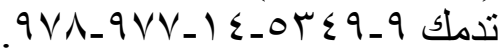

محمد مصطفى السيد.

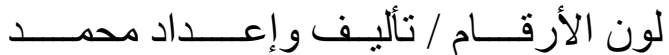

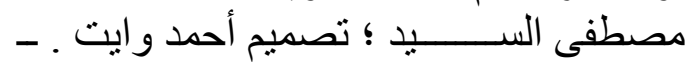

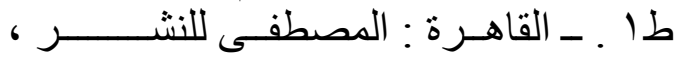
$r .17$

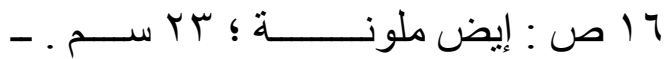

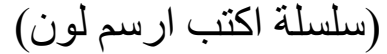

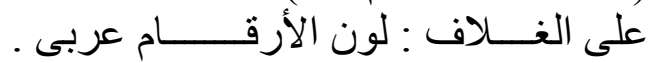
إنجليزى ـ فرنساوى.

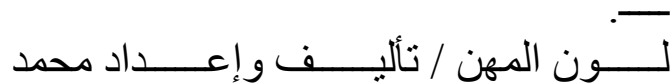

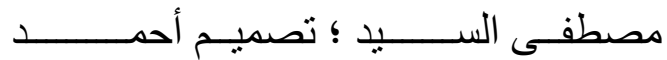

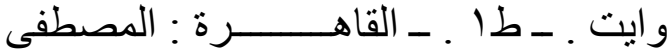
للنشــر ك 17 17 ص : إيض ملونة ؛ بr سم . - (سـلسلة

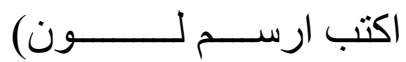

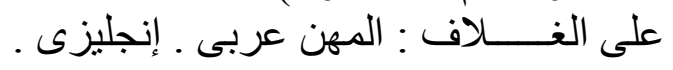

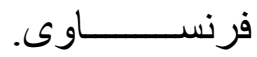

\section{الحيوانات المفترسة}

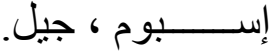

الفهود التلجية / تأليف جيل إبـــبوم ؛ ترجمة

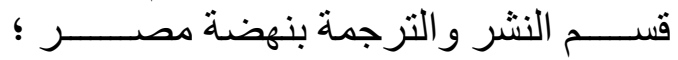

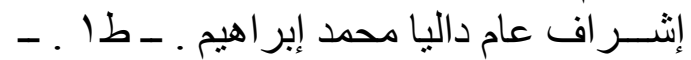

الآلات

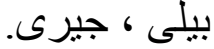

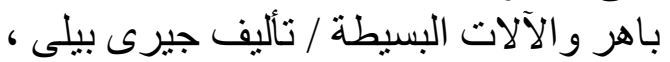

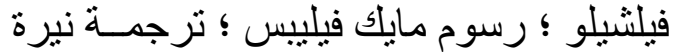

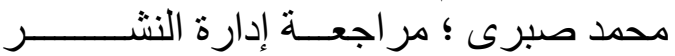

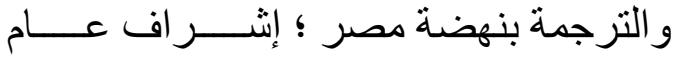

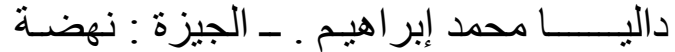

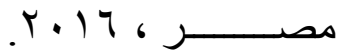

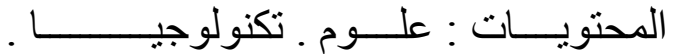

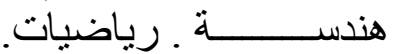

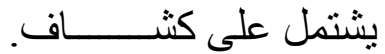
تدمك ع

\section{الأدعية والأوراد}

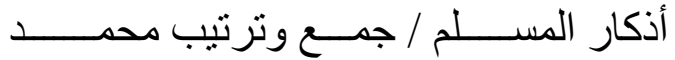

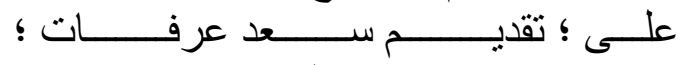

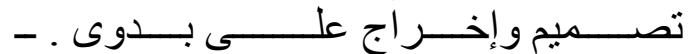

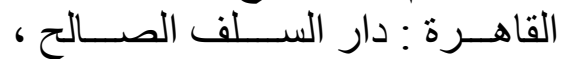
$r \cdot 17$

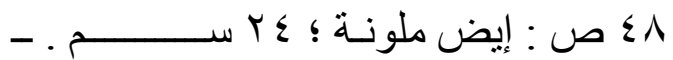

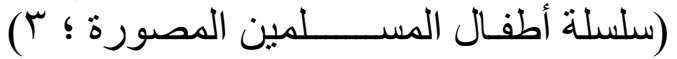

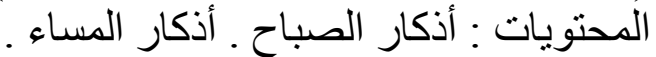

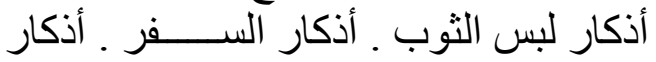

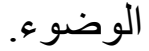

\section{الأغذية ـ مكونات}

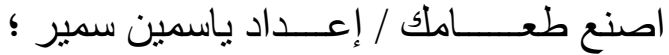

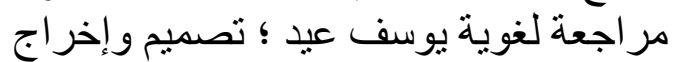

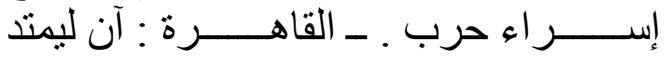

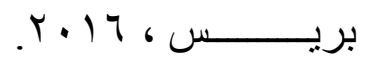

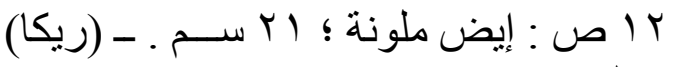
تدمك . . $9 \vee \Lambda_{-}$

التخذية لى ، سالى. 


\section{الطاقة الحركية}

بيلى 6 جيرى

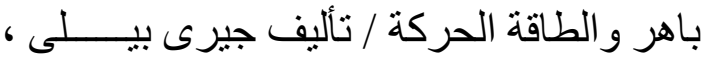

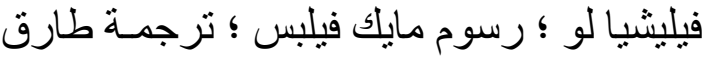

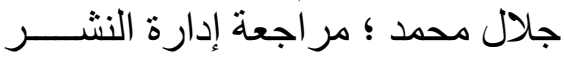

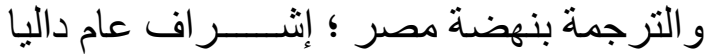

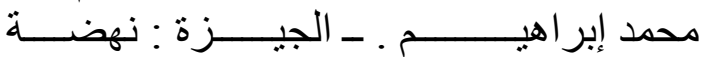

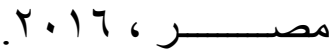

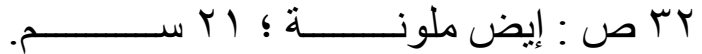

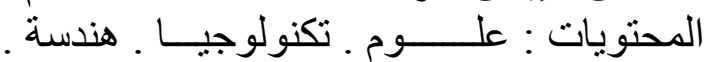

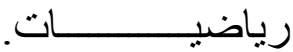
يشتمل على كثاف. . 9 VN_

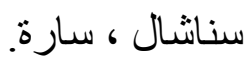
الغابات المطيرة / تأليف ســـارة سناثــــــال ؛

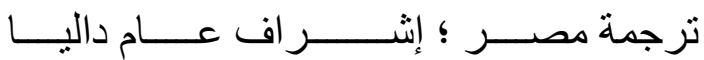

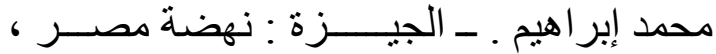
r.

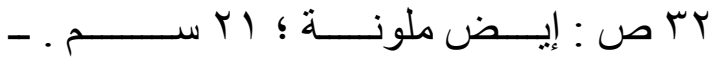

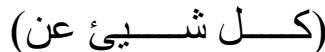

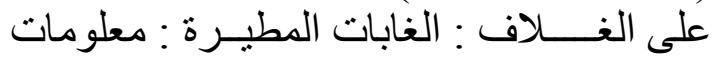

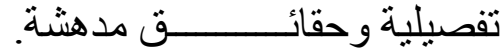
. تدمك

\section{الفر اشـات}

ديلانو ، مارفى فيرجسون.

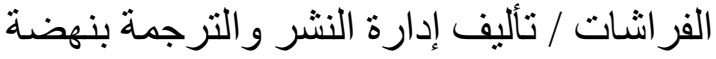

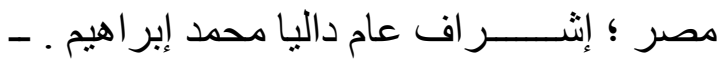

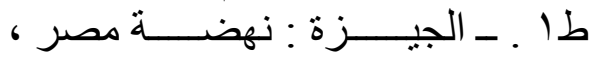
$r \cdot 17$

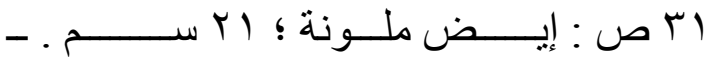

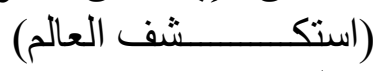

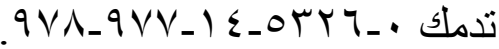

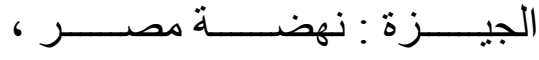
$r \cdot 17$

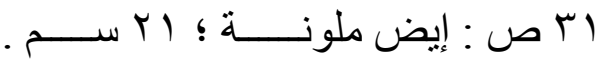

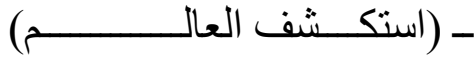

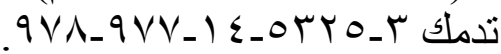

ديلانو ، مارفى فير جسون.

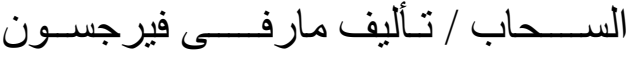
ديلانو ؛ تر جمة إدارة النشـــــر و الترجمة

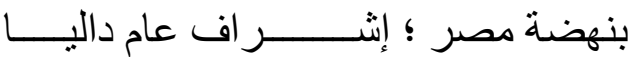

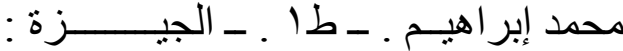

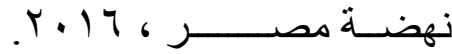

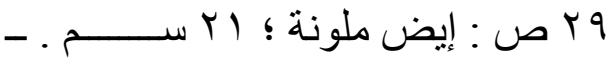

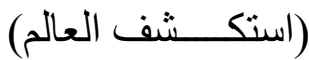

شبكاث الاتصالاث

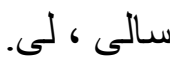

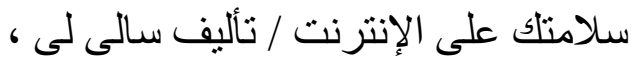

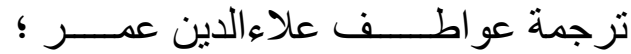

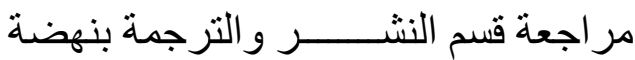

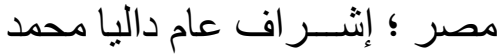

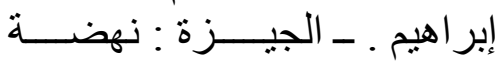
مصــــــــ

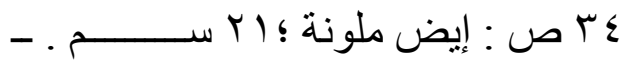
(S) تدمك

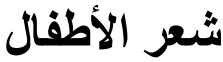
محمود الحلو انــى الهـى

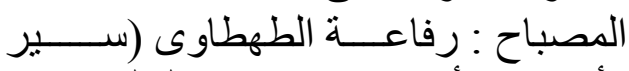
و أشعار ) / أثــــــعار محمود الحلو انــى ؛

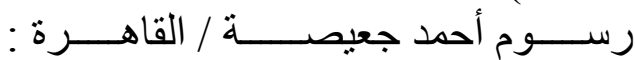

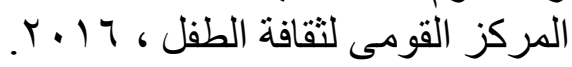

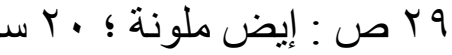
تدملك r . 


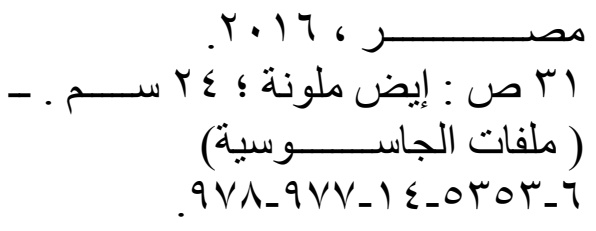

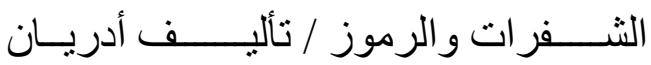

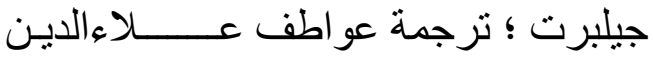

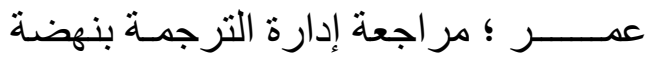

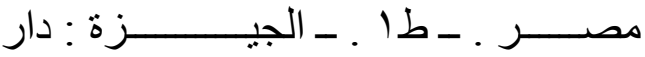

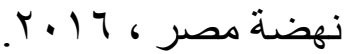

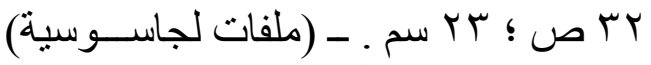
هذا الكتاب ترجمة لـ

Spy files : Godes and ciphers. تدمك $\left.9 \vee \Lambda_{-} 9 V V_{-}\right) \varepsilon_{-} 0$ TOY_

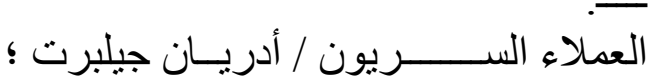

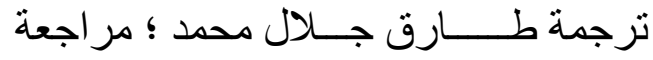

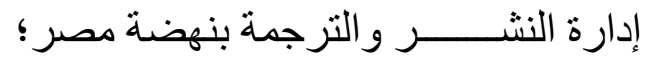

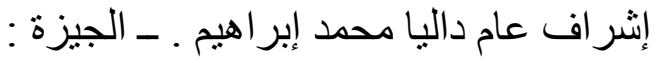

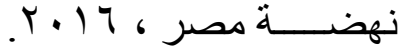

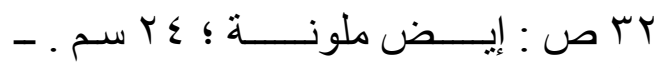

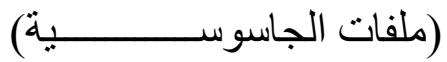
تدمك Y

القصص الدينية

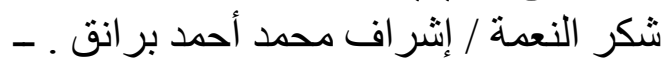

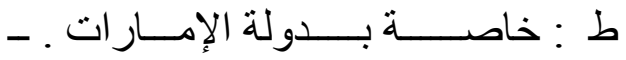

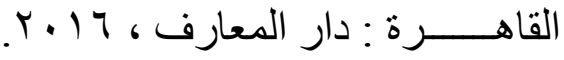

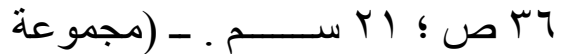
القصص الديني. تدمك

\section{القصص العربية}

أمانى العشماوى.

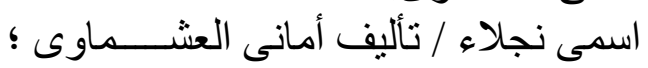

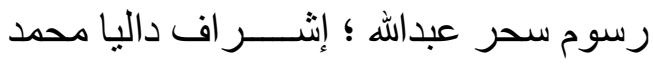

القصص الاجتماعية سلامتلك عند التعامل مع الغرباء / تأليف

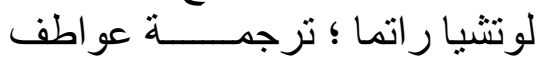

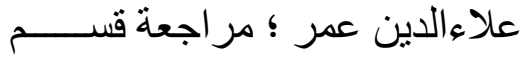

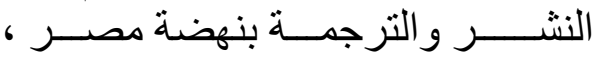
$r \cdot 17$ צ (5)

تدمك

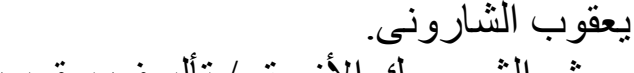

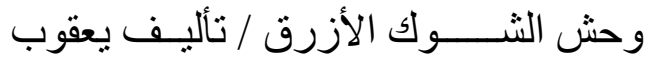

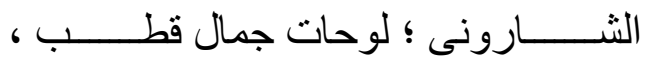

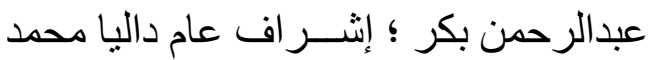

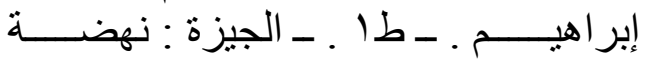

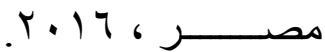

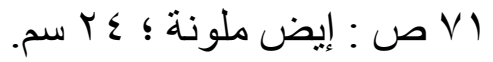

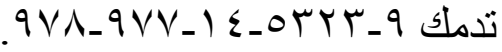

\section{القصص الإنجليزية}

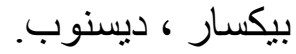

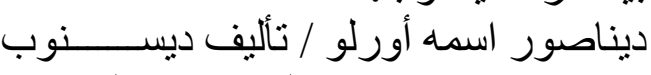

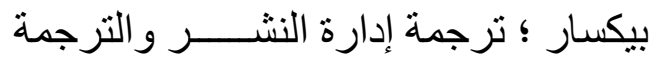

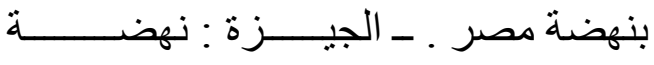

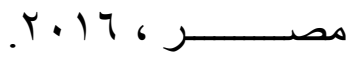

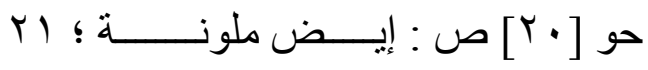

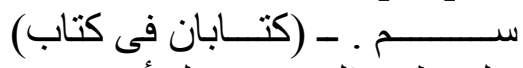

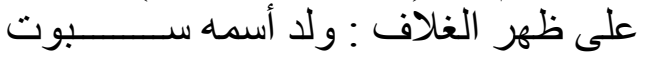

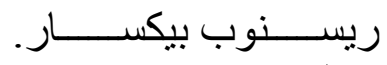
تدمك ع

جيلبرت ، أدريان.

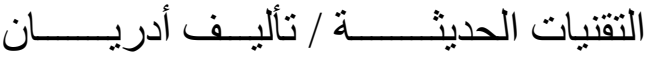

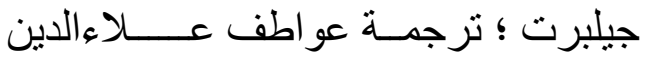

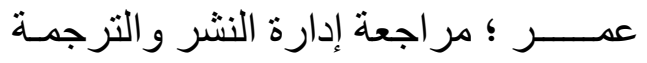

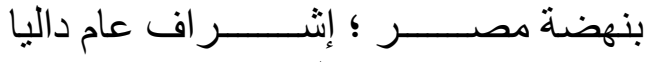

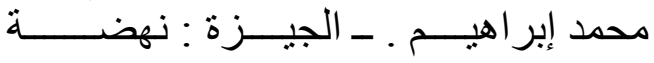




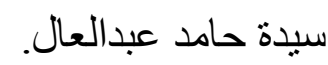

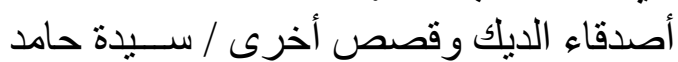

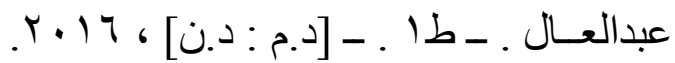

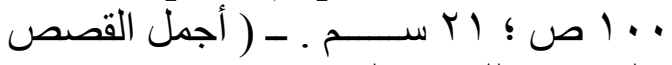

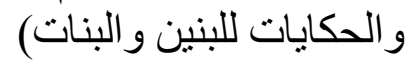

رحلة إسماعيل وقصص أخرى / ســيدة حامد

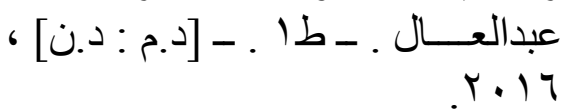

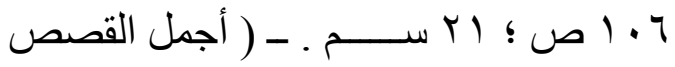
و الحكايات للبنين و البنات)

$$
\text { شهاب سلطان. }
$$

الصقر الأسود / قصة شهاب سلطان ؛ رسـوم

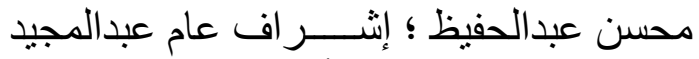

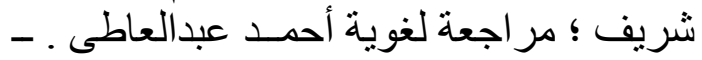

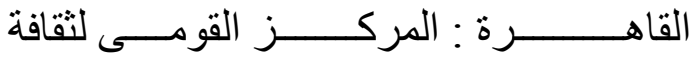
الطف rT ص : إيض ملونة ؛ ؛ تدمك

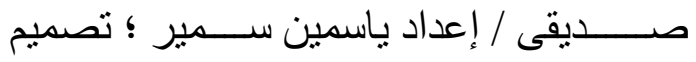

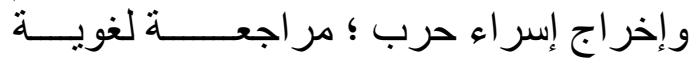

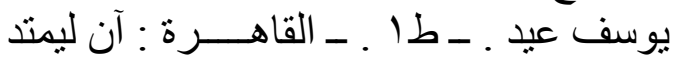

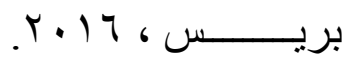

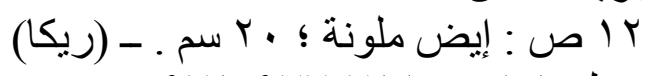
تدمك ا

طيار المستقبل / إعداد خالد موسـى ؛ تصميم

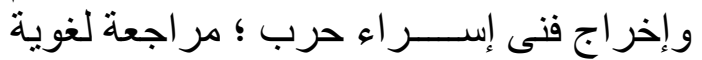

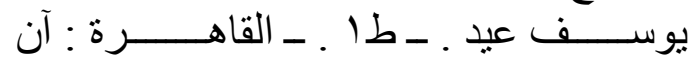

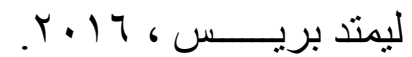

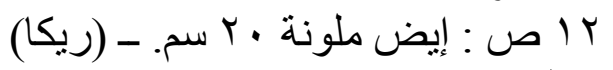

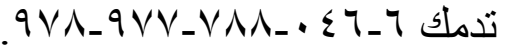

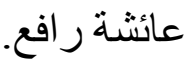
حقيبة النيل : القيم الأخلاقية : الامتنان : تقدير

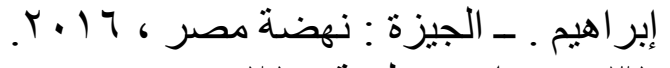

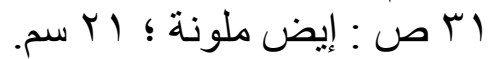

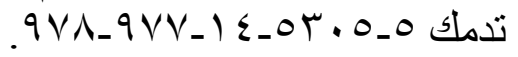

حازم إسماعيل.

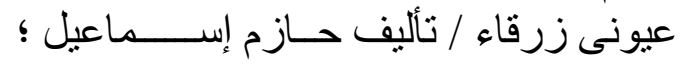

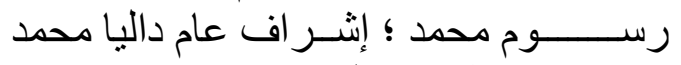

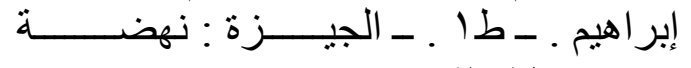

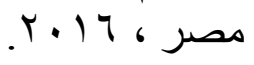

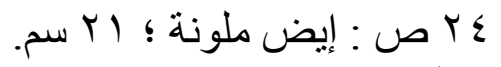
تدمك r

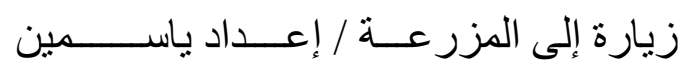

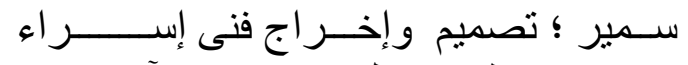

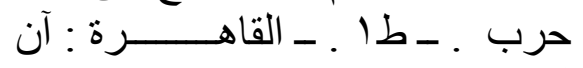

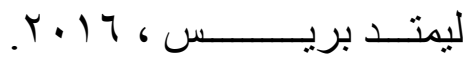

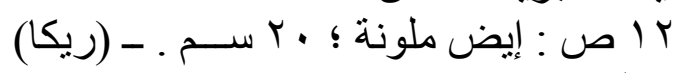

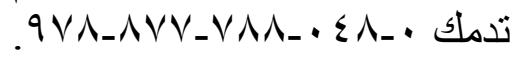

سماح كامل. علبة قطيفة حمـر اء / تأليف ســـماح كامل ؛

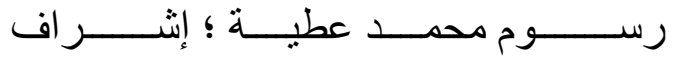

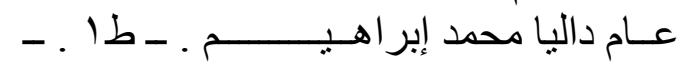

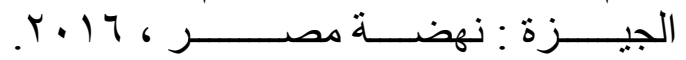
rr ص : إيض ملونة ؛ تدمك r. سمر محفوظ براج.

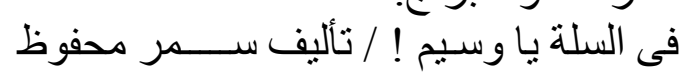

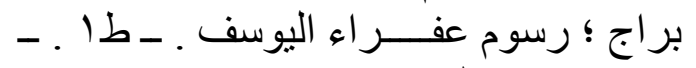

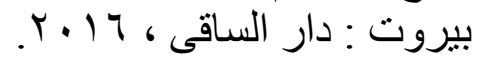

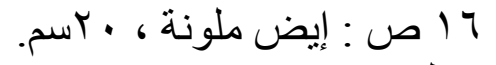

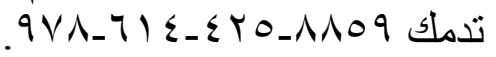

هذه ليست لعبة يا وسيم / تأليف سمر محفوظ

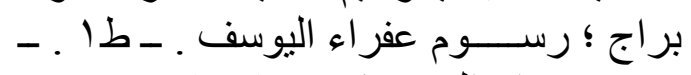

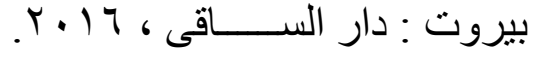

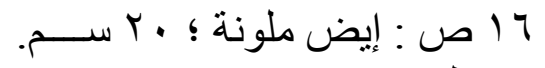
تومـلك 
فصول الســـــنة الأربعة / إعداد باسـمين

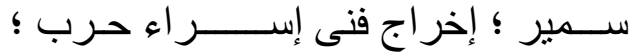

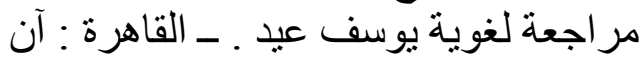

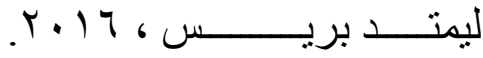

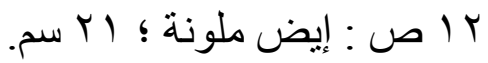
9VA_AVV_VAN_.07_0 تدمك

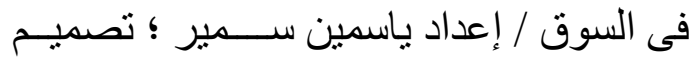

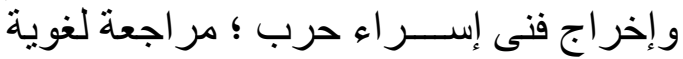

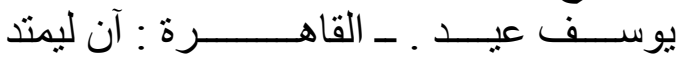

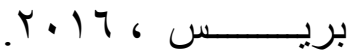

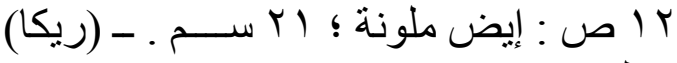

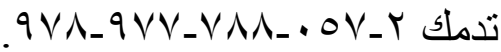

فى الثار ع / إعداد ياسمين ؛ تصميم و إخـراج

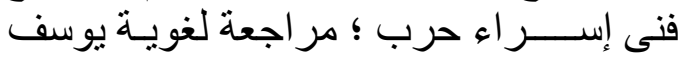

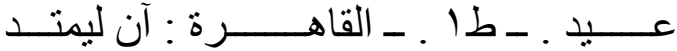

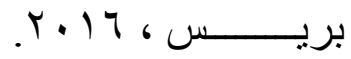

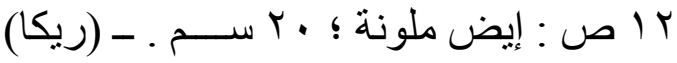

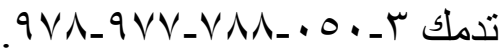

محمد عطية الإبر اثى.

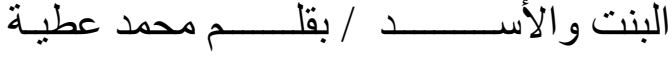

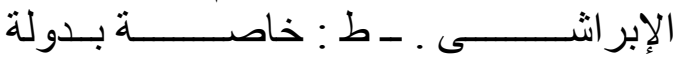

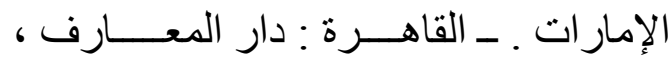
r.1

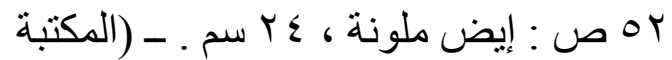

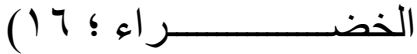
تدمك . .

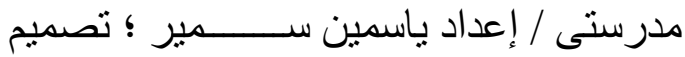

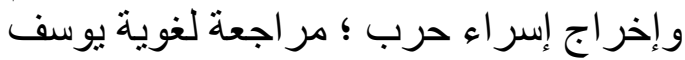

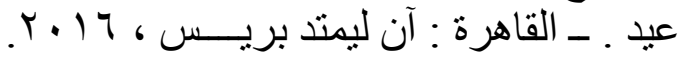

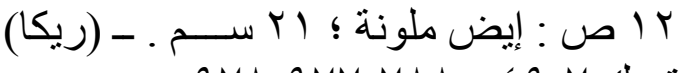

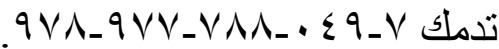

كل إنسان / تأليف عائشة ر افع ؛ رسوم

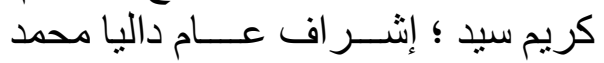
إبر اهيم . ـ طا إ ـ ـ الجيزة : نهضة مصر r. 17 ،

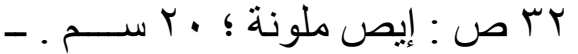

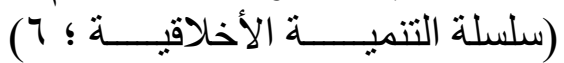

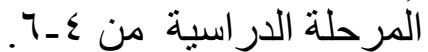

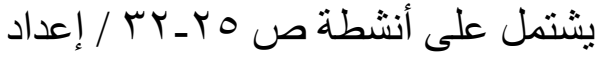

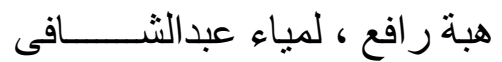
تدمك

الملك الحكـيم : القيم الأخلاقية : الصدق :

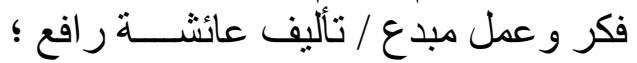

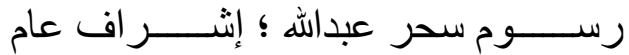

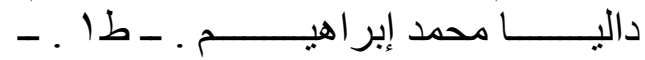

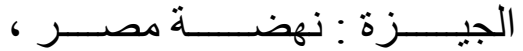
$r \cdot 17$

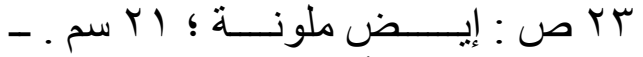

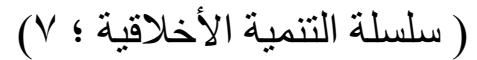

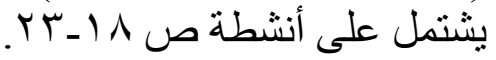

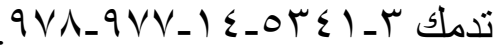

عفاف طبالة. شمس / تأليف عفاف طبالة ؛ رسوم هنادى

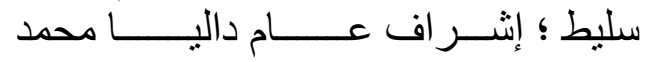

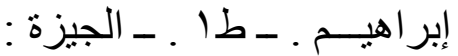

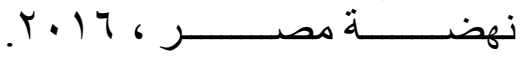

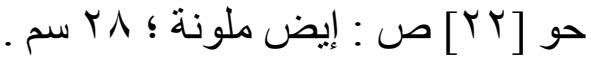
ت 9VA_9VV_) E_OYOY_r

فاطمة شــرف الدين

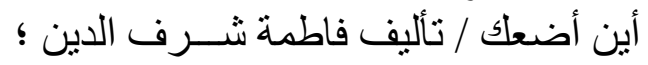

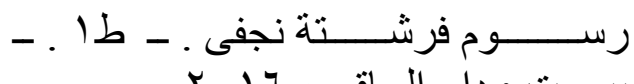

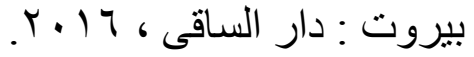
ك تدمك $\left.9 \vee \Lambda_{-} 7\right) \varepsilon_{-} \varepsilon Y 0_{-} 9 \leq \Lambda_{-}$( 


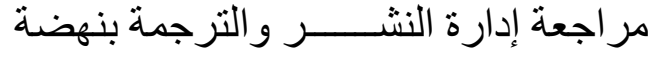
مصر ؛ إثـــر اف عام إدة داليا محمد إبر اهيم .

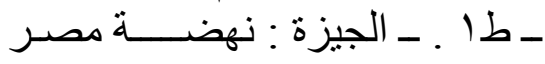
r.1 $7_{6}$

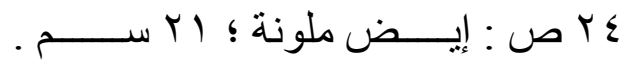

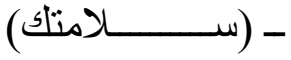
تدمك

$$
\begin{aligned}
& \text { قصص القزآن }
\end{aligned}
$$

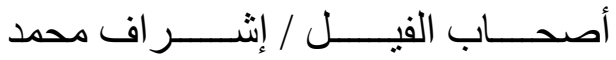

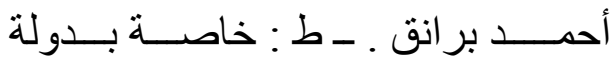

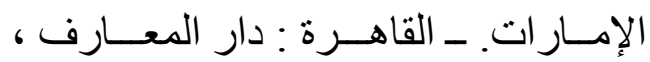

$$
\begin{aligned}
& \text { r. } 17
\end{aligned}
$$

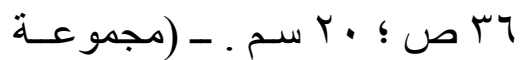

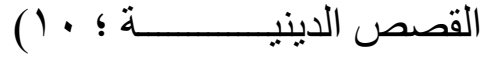

$$
\begin{aligned}
& \text { تدمك ع }
\end{aligned}
$$

لى لى محسن.

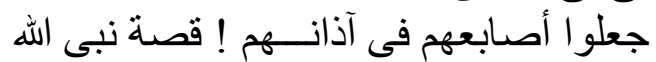

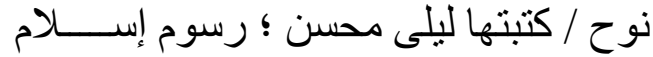

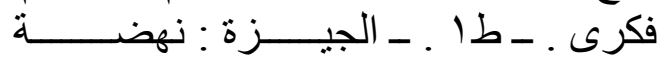

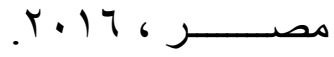

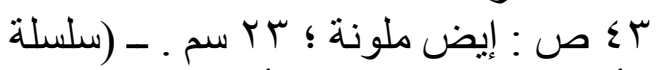

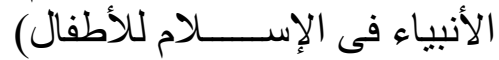

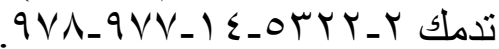

معجز ات الســــماء : قصة نبى الله إبر اهيم

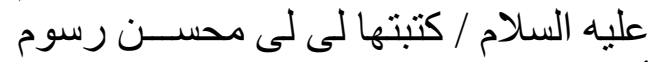
أحمد شوقى ؛ ترجمة إدارة النشر و الترجة الترة

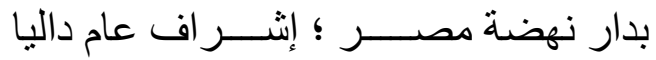

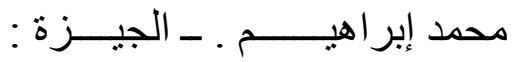

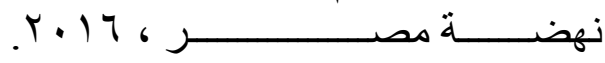

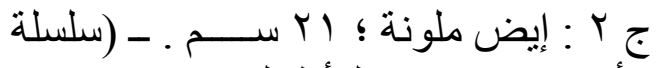

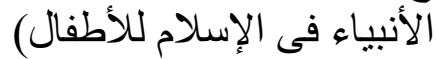
تدمك 9 .

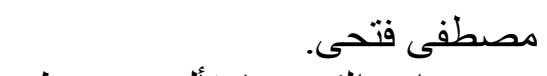

مينو .. ابن القـــر / تأليف مصطفى كـي

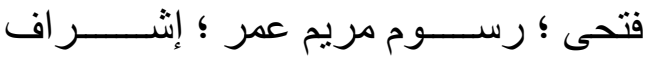

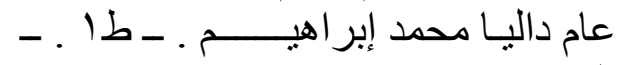

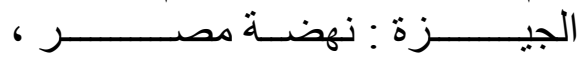
.17

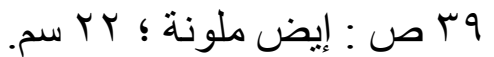

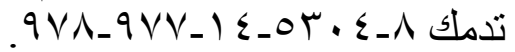
منى لملوم.

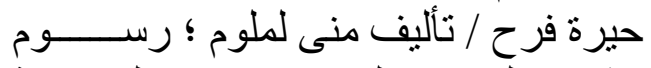

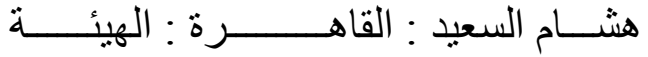

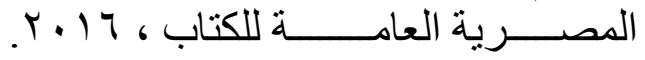

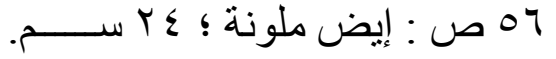

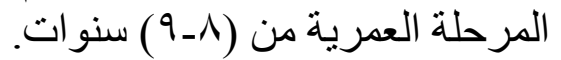

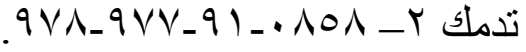

وسائل المواصلات / إعداد ياسمين سمير ؛

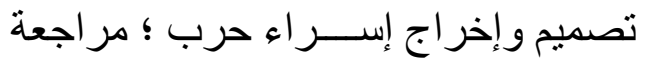

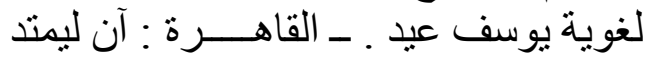

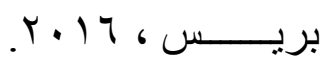

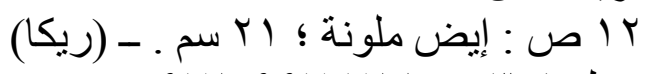

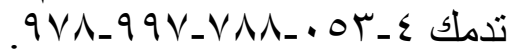

\section{القصص العلمية} راتما ، لوتشيا.

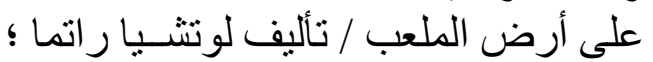

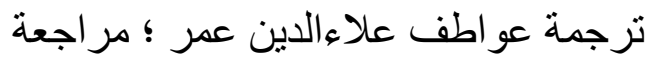

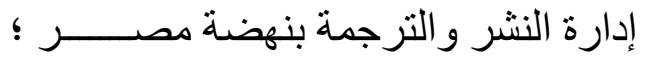

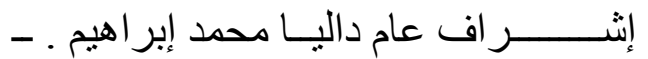

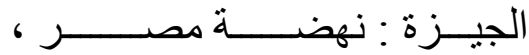
$r \cdot 17$

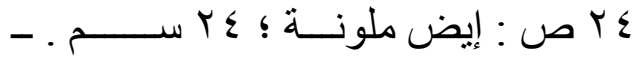

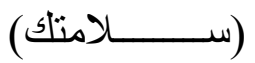
تدمك $\left.9 \vee \Lambda_{-} 9 \vee V_{-}\right) \leqslant-0 r \leqslant V_{-}$

عند اشتعال الحر ائق / تأليف ر اتما لوتشـيا

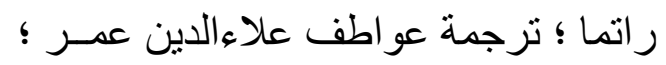




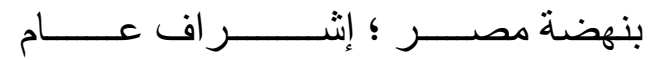

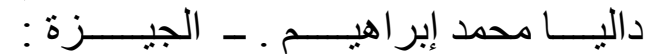

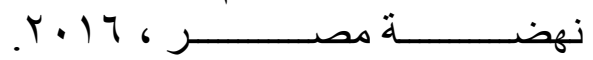

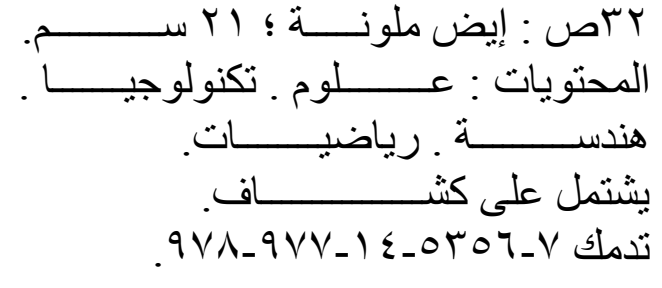
تدمك
النار الباردة : قصـــــة نبى الله إبر اهيم عليه

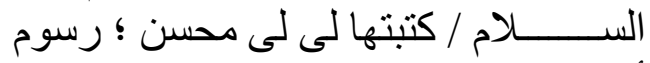
أحمد شوقى ؛ ترجمة إدارة النشر

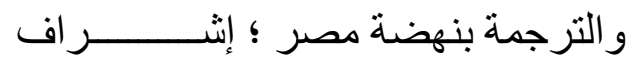

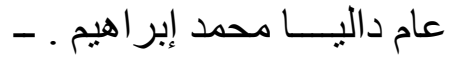

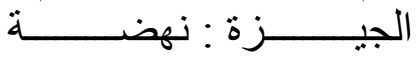

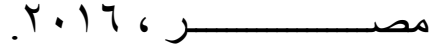

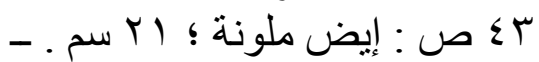
(سلسلة الأنبياء فى الإســـــــــام للأطفال) تدمك AVA_9VV_l

\section{مسر حيات الأطفال}

جيهان ســــــالخم.

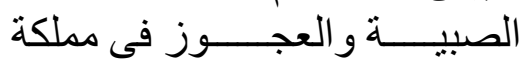

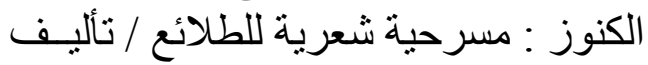

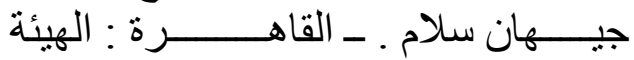

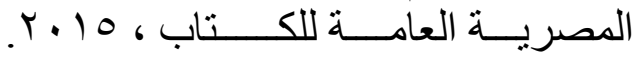

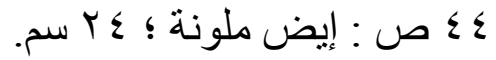

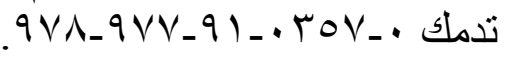

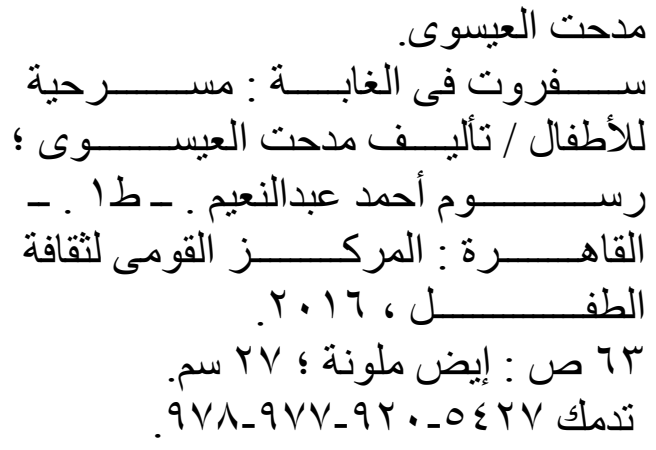

\section{المواد الخام} بيلى ، جيرى.

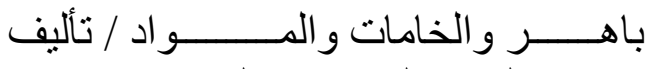

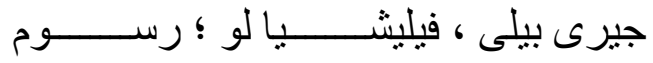

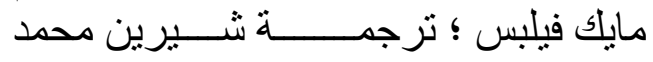
حيدر ؛ مر اجعة إدارة النشـــــــر و الترجمة مجنة 